\title{
Genotoxicity of aflatoxins and their precursors in human cells
}

M.G. Theumer $^{1}$, Y. Henneb ${ }^{1}$, L. Khoury ${ }^{2}$, S.P. Snini, S. Tadrist, C. Canlet, O. Puel, I.P. Oswald, M. Audebert $*, 1$

Toxalim, Université de Toulouse, INRA, INP-ENVT, INP-EI-Purpan, Université de Toulouse 3 Paul Sabatier, Toulouse, France

* Corresponding author

1 These authors contributed equally to this work.

2 Present address: PrediTox, Toulouse, France.

Keywords: Aflatoxin Genotoxicity H2AX Metabolism DNA damage

\begin{abstract}
Aflatoxins are found as food contaminant and some of them demonstrate a carcinogenic effect. The aflatoxins biosynthetic pathway involves 15 successive steps. The aim of this study was to compare the toxicity of afla- toxins and their precursors in three human cell lines. We tested the four aflatoxins and two of their metabolites; three early metabolic precursors and two late biosynthetic precursors. Cyclopiazonic acid, synthesized in parallel with aflatoxins, was also tested. The cytotoxicity and the genotoxicity was evaluated with the $\gamma \mathrm{H} 2 \mathrm{AX}$ assay in three human cell lines with different bioactivation capacities. Our results indicated that the most genotoxic chemicals in the three cell lines were in decreasing order sterigmatocystin (ST), aflatoxin B1 (AFB1), aflatoxicol (AFL), aflatoxin G1 (AFG1) and versicolorin A (VERA). Aflatoxin M1 (AFM1) demonstrated genotoxic property in only one cell line. The other tested compounds did not demonstrate any genotoxic activity. Overall, our results suggested different genotoxic mechanisms of action for the tested compounds, involving specific bioactivation pathways. Moreover, some metabolic precursors of aflatoxins demonstrated genotoxic potential equivalent or greater to AFB1. This should be taking into account for the development of new strategies intended to reduce the aflatoxins exposure and for human risk assessment.
\end{abstract}

\section{Introduction}

Aflatoxins are fungal secondary metabolites produced by several Aspergillus species from the flavi section which infect several food commodities (Paterson and Lima, 2010). Aflatoxins constitute a group of closely related compounds, that have strong detrimental impact on the public health and the economy (Kensler et al., 2011). Aflatoxin B1 (AFB1) is the most potent naturally occurring carcinogen reported to date (classified as Group 1 by IARC), having hepatotoxic, immunotoxic and teratogenic properties (IARC, 2012). The most important target organ of AFB1 is the liver (Meissonnier et al., 2007), where the toxin is metabolized principally by CYP1A2 and CYP3A4 resulting in DNA ad- ducts formation (Oda et al., 2001) and cause numerous mutations, notably in the p53 tumor suppressor gene (Eaton and Gallagher, 1994; Kensler et al., 2011). Moreover, prostaglandin $\mathrm{H}$ synthase could also metabolize AFB1 in a mutagenic chemical (Battista and Marnett, 1985). AFB1 has also been reported to induce an oxidative stress in vivo (Guindon et al., 2007) as well as in vitro (Parveen et al., 2014), independently of enzymatic bioactivation. However, it is important to recall the probably interactive effects of some 
well documented AFB1 co-occuring risk factors, such as chronic hepatitis B and C infections, in the hepatocellular carcinoma (HCC) development (Hamid et al., 2013).

The current knowledge on the aflatoxins production indicates that at least 30 genes are involved in the aflatoxins biosynthesis and are clustered within a $75 \mathrm{~kb}$ region of the fungal genome located roughly $80 \mathrm{~kb}$ away from telomere (Yu, 2012). About fifteen intermediates form the entire aflatoxin biosynthetic pathway (Fig. 1) and each of them could be found in contaminated food and feed (Streit et al., 2013; Varga et al., 2013). Several strategies have been developed to limit the AFB1 exposure (Holmes et al., 2008; $\mathrm{Wu}$ and Khlangwiset, 2010). They include resistant crops, agricultural practices management, and the use of microorganisms, natural products or chemicals that alter known environmental and physiological modulators of aflatoxins biosynthesis, or they alter signaling transduction pathways in the upstream regulatory network. Nevertheless, attempts to reduce the food contamination with aflatoxins may also induce the accumulation of any/several aflatoxin intermediates, or even other metabolic pathway products such as the cyclopiazonic acid (CPA), whose toxicities were not fully explored yet, notably in human cells. Strategies that aimed to interrupt its bio- synthesis lead us to wonder about the toxicity of these intermediates or even other metabolic pathway product like cyclopiazonic acid.

Most toxicity studies only focused on some aflatoxins or on its hydroxylated metabolite (AFM1). We previously demonstrated, using human cell lines with distinct biotransformation properties, the efficiency of the $\gamma \mathrm{H} 2 \mathrm{AX}$ ICW genotoxic assay to determine the genotoxic potential of AFB1 (Khoury et al., 2013; Khoury et al., 2016b). The aim of the present study was to compare the cytotoxicity and the genotoxicity potential of twelve molecules: the aflatoxins and their meta- bolites (AFB1, AFB2, AFG1, AFG2, AFM1 and aflatoxicol (AFL)); five intermediates: the sterigmatocystin (ST), the 0 methylsterigmatocystin (OMST), the averantin (AVE), the norsolorinic acid (NOR) and the versicolorin A (VERA); and one co-metabolite: the cyclopiazonic acid (CPA). The $\gamma \mathrm{H} 2 \mathrm{AX}$ ICW assay was used to simultaneously determine cytotoxicity and genotoxicity of these molecules. Three human cell lines, with a wild type p53 status, derived from target organs of mycotoxins were used. Two cell lines expressing phase I and II bioactivation capabilities (LS-174T (colon) and HepG2(liver)), and one with very poor general bioactivation property (ACHN (kidney)) (Khoury et al., 2016b) to highlight we link between the biotransformation process of a chemical and its genotoxic potential.

\section{Materials and methods}

Chemicals

AFB1, AFB2, AFG1, AFG2 and AFM1; ST, OMST, and CPA were purchased from SigmaAldrich (Saint Quentin Fallavier, France). Averantin was provided by BioViotica Naturstoffe GmbH (Dransfeld, Germany). AFL was purchased from Fermenteck (Jerusalem, Israel). NOR and VERA were purified from wheat inoculated with Aspergillus toxigenic stocks, as described below. Almost all stock solutions of the compounds were prepared in 100\% dimethyl sulfoxide (DMSO). From the stocks, 10 -fold dilution series were prepared. Penicillin, strepto- mycin, trypsin, PBS, RNAse A, and Triton X-100 were purchased from Sigma-Aldrich (Saint Quentin Fallavier, France). The phosphatase inhibitor cocktail tablets ("PHOSSTOP") were purchased from Roche (Meylan, France), and the blocking solution (MAXblock Blocking Medium) was purchased from Active Motif (Rixensart, Belgium). CF770 antibody and RedDot2 were purchased from Biotium (Hayward, California, USA). All solvents used in the extraction and high performance liquid chromatography (HPLC) analysis were analytical grade and purchased from Fisher 
Scientific (Illkirch, France). Water for HPLC- DAD and molecular biology procedures was purified by using a Millipore MilliQ purification system.

\section{Fungal strains}

A. nidulans RAV Pyro 2, a highly NOR producer mutant, was kindly provided by Pr. AM Calvo, Department of Biological Science, Northern Illinois University, DeKalb, Illinois, USA. The $A$. parasiticus SRRC 0164, a highly VERA producer mutant, was kindly provided by S. Beltz, Southern Regional Research Center, Agricultural Research Service/ United States Department of Agriculture, New Orleans, USA.

\section{Production, isolation and purification of NOR and VERA}

For NOR production, A. nidulans RAV Pyro 2 was cultivated on solid $1 \%$ oat meal agar. The inoculated plates were incubated for 7 days at $37^{\circ} \mathrm{C}$, and then the mycelium was harvested and extracted overnight with chloroform. The chloroformic extract was filterclarified thanks to Whatman ${ }^{\circledR}$ 1PS phase separator filter papers (Whatman, GE Healthcare, Kent, UK) and evaporated to dryness in a rotary evaporator and then with a Zymark TurboVap (McKinley Scientific, Sparta, NJ, United States) with dry nitrogen. The residue was kept at $-20^{\circ} \mathrm{C}$ until NOR purification by chromatography. VERA was obtained from wheat fermented by $A$. parasiticus SRRC 0164. Briefly, the mutant strain was grown in potato dextrose agar (PDA) plates for 7 days at $28{ }^{\circ} \mathrm{C}$, and thereafter small portions of the developed medium were transferred and dispersed in $14 \mathrm{~cm}$ diameter Petri dishes containing autoclaved wheat with $35 \%$ humidity. The inoculated plates were incubated for 7 days at $28{ }^{\circ} \mathrm{C}$. At the end of the incubation period, wheat and mycelium were harvested and extracted overnight with chloroform. The chloroformic extract was filterclarified and evaporated to dryness as previously described. The residue was kept at $-20^{\circ} \mathrm{C}$ until VERA purification by chromatography.

The purification of NOR and VERA was performed with an Ultimate 3000 HPLC system (Dionex/ThermoScientific, Courtaboeuf, France). A Strategy C18-2 semi-preparative column was used $(250 \mathrm{~mm}$ length, $7.8 \mathrm{~mm}$ internal diameter and $5 \mu \mathrm{M}$ particular size (Interchim, Montluçon, France). The purification of the two compounds was achieved by gradient elution using $0.2 \%$ acetic acid (eluent A) and acetonitrile (eluent B) as mobile phase at a flow rate of $2.4 \mathrm{~mL} / \mathrm{min}$ for NOR and at a flow rate of $4.2 \mathrm{~mL} / \mathrm{min}$ for VERA. The preparative flow was pumped through a valve at the ultimate 3000 Fraction Collector (Dionex/ThermoScientific).

For NOR purification, the elution started with $50 \%$ solvent B over 10 min. The solvent B part increased then to $90 \%$ within $5 \mathrm{~min}$. After a $15 \mathrm{~min}$ isocratic elution, the gradient decreased to the initial value within $5 \mathrm{~min}$ and remained constant for the last $10 \mathrm{~min}$. For VERA purification, the elution started with $46 \%$ solvent B over $10 \mathrm{~min}$. The part of the solvent B increase then to $50 \%$ within $14 \mathrm{~min}$ and increase again to $90 \%$ within $4 \mathrm{~min}$. After a 5 min isocratic elution gradient decreased to the initial value within 5 min and remained constant for the last $5 \mathrm{~min}$. For the two molecules, multiple fractions were pooled, and the solvent was evaporated under reduced pressure. Prior to toxi- city experiments, the identity and purity of the purified metabolites were confirmed by several methods described below.

\section{HPLC-DAD analysis}

HPLC-DAD analysis was performed on the same apparatus described above. A Zorbax C18 analytic column was used $(150 \mathrm{~mm}$ length, $4.6 \mathrm{~mm}$ internal diameter and $5 \mu \mathrm{M}$ particular size, Interchim). In order to check the norsolorinic acid purification a gradient program 
was used with $0.2 \%$ acetic acid (eluent $\mathrm{A}$ ) and acetonitrile (eluent $\mathrm{B}$ ) as mobile phase at a flow rate of $2.4 \mathrm{~mL} / \mathrm{min}$. The elution started with $50 \%$ sol- vent B over $10 \mathrm{~min}$, then the gradient increased to $90 \%$ within $5 \mathrm{~min}$. After $15 \mathrm{~min}$ isocratic elution, the gradient decreased to $50 \%$ within $5 \mathrm{~min}$ and remained constant for the last $10 \mathrm{~min}$. The presence of NOR was monitored at a wavelength of $305 \mathrm{~nm}$ and $463 \mathrm{~nm}$. For the verification of the VERA purification a gradient program was used with the same solvents and the following elution conditions were used: $0-8 \mathrm{~min} 45 \%$ B (flow $1.6 \mathrm{~mL} / \mathrm{min}$ ), then the flow rate decreased to $1.4 \mathrm{~mL} / \mathrm{min}$ and the solvent B part decreased to $35 \%$ within $4 \mathrm{~min}$. After 48 min isocratic elution, the flow rate increased to $1.6 \mathrm{~mL} / \mathrm{min}$ and the gradient increased to the initial value within $4 \mathrm{~min}$ and remained constant for the last $6 \mathrm{~min}$. The presence of VERA was monitored at a wavelength of $287 \mathrm{~nm}$.

\section{High-resolution mass spectrometry analyses}

The identity of the two purified compounds was confirmed by liquid chromatography coupled to a high resolution mass spectrometer LTQ Orbitrap XL (Thermo scientific, San Jose, CA, United States), and fitted with an electrospray ionization mode according to Cano et al. (2013). A reverse phase $150 \times 2.0 \mathrm{~mm}$ Luna C18 (2) column (Phenomenex, Torrance, $\mathrm{CA}$, United States) was used. Twenty $\mu \mathrm{L}$ of methanol dilution of each purified compound were injected directly in the LC system. The flow rate was $0.2 \mathrm{~mL} / \mathrm{min}$. the gradient chromatography was performed with $0.1 \%$ acetic acid (eluent $\mathrm{A}$ ) and acetonitrile (eluent B) as mobile phase. The elution started with a linear gradient ranging $20 \%$ to $50 \%$ for 30 min. Then the solvent B part increased to $90 \%$ within 5 min. After a 10 min isocratic elution, the gradient was decreased to initial value within $5 \mathrm{~min}$ and remained at this value for the last $10 \mathrm{~min}$. Electro- spray ionization was performed at $4.5 \mathrm{kV}$. The temperature and voltage were set respectively to $350{ }^{\circ} \mathrm{C}$ and $40 \mathrm{~V}$. Resolution was set to 60000 for $\mathrm{m} / \mathrm{z}$ range set to $50-800$.

\section{Nuclear magnetic resonance analyses}

$1_{\mathrm{H}}$ and two-dimensional nuclear magnetic resonance (2D-NMR) spectra were obtained on a Bruker DRX-600 Avance NMR spectrometer (Bruker, Wissembourg, France) operating at $600.13 \mathrm{MHz}$ for ${ }^{1} \mathrm{H}$ re- sonance frequency, using an inverse detection $5 \mathrm{~mm}$ $1 \mathrm{H}-13 \mathrm{C}-15 \mathrm{~N}$ cryoprobe in $\mathrm{CDCl} 3$ solution (70-200 $\mu \mathrm{g}$ sample/600 $\mu \mathrm{L}$ solvent in a $5 \mathrm{~mm}$ NMR tube). To confirm the chemical structures, samples were analyzed using 2D-NMR including gradient selection (gs)-correlation spectroscopy (COSY), (gs)-heteronuclear single quantum coherence (HSQC) and (gs)-heteronuclear multiple bonding connectivity (HMBC). ${ }^{13} \mathrm{C}$ chemical shifts were determined from the $\mathrm{f} 1$ projection of HSQC and HMBC diagrams, because the low amount of product precluded the direct measurement of a carbon spectrum.

Norsolorinic acid exhibited the following properties: ${ }^{1} \mathrm{H}$ NMR $(600 \mathrm{MHz}, \mathrm{CDCl} 3) \delta \mathrm{ppm}$ : $7.19(1 \mathrm{H}, \mathrm{s}, \mathrm{H}-4)$; $7.14(1 \mathrm{H}, \mathrm{d}, \mathrm{J}=2.5 \mathrm{~Hz}, \mathrm{H}-5) ; 6.53(1 \mathrm{H}, \mathrm{d}, \mathrm{J}=2.5 \mathrm{~Hz}, \mathrm{H}-7) ; 3.12$ (2H, t, J = $7 \mathrm{~Hz}, \mathrm{H}-12$ ); 2.18 (2H, t, H-13); 1.45 (2H, m, H-14); 1.25 (2H, m, H-15); 0.88 (3H, t, H-16). ${ }^{13}$ C NMR (150 MHz, CDCl3) $\delta$ ppm: 164.5 (C-6); 163.0 (C-3); 134.5 (C-4a); 134.2 (C-5a); 121.5 (C-2); 108.6 (C-4); 108.5 (C-1a); 108.3 (C-8a); 108.2 (C-5); 107.4 (C-7); 43.5 (C-12); 30.2 (C-13); 22.5 (C-14); 21.3 (C- 15); 13.8 (C-16); and HR-MS (negative ESI): m/z 369.09785 (M-H) ${ }^{-}$(calculated exact mass: 369.0980; deviation (ppm) -0.342). For VERA, HRMS and NMR data were in agreement with the data previously published (Jaksic et al., 2012). 


\section{Cell lines and cultures}

HepG2 human hepatoblastoma cells (ATCC No. HB-8065), ACHN human renal cell adenocarcinoma cells (ATCC No. CRL-1611), and LS- 174T human epithelial colorectal adenocarcinoma cells (ATCC No. CL- 188) were cultured in $\alpha \mathrm{MEM}, 10 \%$ fetal calf serum $\mathrm{v} / \mathrm{v}$, penicillin effective concentration (LEC) for $\gamma \mathrm{H} 2 \mathrm{AX}$ induction in each cell line (Audebert et al., 2012). AFB1 was choice as the reference compound for GEF determination (set to 1 ).

\section{$\gamma H 2 A X$ in-cell western (ICW) assay}

The $\gamma \mathrm{H} 2 \mathrm{AX}$ In-Cell Western technique was performed as previously described (Khoury et al., 2013; Khoury et al., 2016a,b; Quesnot et al., 2016). Briefly, HepG2, ACHN and LS174-T cells were seeded $16 \mathrm{~h}$ prior to treatment at a density of $3.2 \times 104$ cells per well in 96 -well micro- plates, exposed to chemicals for $24 \mathrm{~h}$, fixed with $4 \%$ paraformaldehyde (Electron Microscopy Science, Pelanne Instruments, France) in Phosphate Buffered Saline (PBS) and permeabilized with $0.2 \%$ Triton X-100. Cells were then incubated in blocking solution (MAXblock Blocking Medium supplemented phosphatase inhibitor PHOSSTOP and $0.1 \mathrm{~g}$. L-1 RNAse A) prior to $2 \mathrm{~h}$ incubation at room temperature with rabbit monoclonal anti$\gamma \mathrm{H} 2 \mathrm{AX}$ (Clone 20E3, Cell signaling) primary antibody in PST buffer. Detection was carried out with an infrared fluorescent dye conjugated to goat antibody (CF770, Biotium). For DNA labeling, RedDot2 (Biotium) was added simultaneously to the secondary anti- body. After $1 \mathrm{~h}$ of incubation, the fluorescence was measured using an Odyssey Infrared Imaging Scanner (Li-CorScienceTec, Les Ulis, France). The fluorescence corresponding to $\gamma \mathrm{H} 2 \mathrm{AX}$ and co-localizing with RedDot2 was integrated and expressed as fold change compared with negative controls. Cell viability was calculated by Relative cell count [RCC or final cell count (treated)/final cell count (control) $\times 100]$ assessed by automated fluorescence. All experiments were performed at least three times independently.

\section{Data analysis}

Genotoxicity was considered positive when a compound produced a statistically significant 1.5 -fold $\gamma \mathrm{H} 2 \mathrm{AX}$ induction at level of cytotoxicity below $50 \%$ compared to the control. These parameters were based on our previous studies (Khoury et al., 2013; Khoury et al., 2016a,b; Quesnot et al., 2016) and are similar to those used by other groups who use $\gamma$ H2AX quantification (Ando et al., 2014; Bryce et al., 2014; Smart et al., 2011). Error bars represent the standard error of the mean (SEM). Statistically significant increases in H2AX phosphorylation after treatment were compared with controls using Student's test $\left(*, \mathrm{p}<.05 ;{ }^{* *}, \mathrm{p}<.01\right)$.

\section{Genotoxic equivalent factor (GEF) determination}

Genotoxic Equivalent Factors (GEF) for aflatoxins and their pre- cursors was determined based on the comparison of their lowest

\section{Results}

First, we examined the cytotoxicity and genotoxicity of the four aflatoxins and two of their metabolites in the three selected human cell lines (Fig. 2). AFB1 and AFG1 demonstrated a genotoxic potential in all the cell lines tested with different potencies. The lowest effective con- centration (LEC) for AFB1 in HepG2, LS-174T and ACHN cells were 1, 0.1 and $10 \mu \mathrm{M}$, respectively (Fig. 2A). For AFG1, the observed LEC were 10, 1 and $100 \mu \mathrm{M}$ in HepG2, LS-174T and ACHN, respectively (Fig. 2B). These two compounds demonstrated 
some cytotoxicity at high concentrations, notably in the LS-174T cell line. AFM1 was genotoxic only at the highest concentration tested $(10 \mu \mathrm{M})$ and only in the LS-174T cells (Fig. 2F) without any sign of cytotoxicity. AFL was genotoxic without any sign of cytotoxicity in HepG2 and LS-174T cells with a LEC of 10 and $0.1 \mu \mathrm{M}$, respectively (Fig. $2 \mathrm{E})$. We observed that AFB2 and AFG2 were not cytotoxic nor genotoxic whatever the cell line tested (Fig. 2C and 2D). Based on these results the genotoxic potencies of aflatoxins were in the following order: AFB1, AFG1 and aflatoxicol > AFM1.

Then we examined the cytotoxic and genotoxic potential of the five aflatoxins precursors and one co-metabolite in the three selected human cell lines (Fig. 3). OMST, AVE, NOR and CPA were cytotoxic in the three cell lines at the highest concentration tested $(100 \mu \mathrm{M})$ but did not demonstrated any genotoxic potential (Fig. 3B, 3D, 3E and 3F). ST and VERA were genotoxic in all the cell lines tested with different potencies. For ST, a LEC of $0.1 \mu \mathrm{M}$ was observed in LS-174T cells and $1 \mu \mathrm{M}$ in HepG2 and ACHN cell lines (Fig. 3A). For VERA, the observed LEC was $1 \mu \mathrm{M}$ whatever the cell line tested (Fig. 2C). VERA demonstrated also high cytotoxicity notably in LS-174T and ACHN cells. Based on these results the genotoxic potencies of aflatoxins precursors were in the following order: ST > VERA.

\section{Discussion}

Aflatoxins are frequently found as food contaminant and some of them demonstrate a carcinogenic effect. The aflatoxins biosynthetic pathway lead to different precursors. Strategies to limit the exposure to aflatoxins may lead to the accumulation of these compounds. However, the genotoxic potential of these chemicals has not been studied completely in a human cellular background. For this reason, we performed a strict comparison of the cytotoxic and the genotoxic potentials of twelve aflatoxins and their precursors using the $\gamma \mathrm{H} 2 \mathrm{AX}$ ICW assay in three human cell lines with different bioactivation properties. We observed that the LS-174T cell line was the most sensitive cells with seven chemicals detected genotoxic and with the lowest LEC, as low as $0.1 \mu \mathrm{M}$ for ST, AFL and AFB1, compared to the other cell lines. Conversely, in the ACHN cells, only four compounds were detected genotoxic and with relative high LEC (AFB1, AFG1, ST and VERA).

We determined the genotoxic equivalent factor (GEF) for each of the tested chemicals compared to AFB1 in each cell line tested (Table 1). This concept of GEF was already applied to other carcinogenic food contaminant like polycyclic aromatic hydrocarbon (Audebert et al., 2012). We observed that all the compounds genotoxic with the $\gamma \mathrm{H} 2 \mathrm{AX}$ assay in the LS-174T cell line were also carcinogenic, confirming the good predictivity of this assay (Khoury et al., 2016b). We noted that for some compounds, GEF between cell lines was unrelated, notably be- tween HepG2 and LS-174T cells on one hand and ACHN cells on the other hand. Difference in the bioactivation capacities of the cell lines used may account for this observation. ACHN cells have very low phase I and II metabolism capabilities (Khoury et al., 2016b). This characteristic may explain the poor genotoxic potential of AFB1, AFG1 and AFL in this cell line. Indeed these later toxins need CYPs bioactivation to induce DNA damage (Oda et al., 2001). The bioactivation of these compounds by the prostaglandin $\mathrm{H}$ synthase (Battista and Marnett, 1985) and/or the induction of an oxidative stress (Guindon et al., 2007; Parveen et al., 2014), may account for the genotoxicity of these aflatoxins in this specific cell line devoid of an important CYPs bioactivation capacity. Conversely, the higher bioactivation capacity of LS-174T compared to HepG2 cells may explain that AFM1 was only genotoxic in the colon cell line. This particularity may be notably related to the phase II enzyme capabilities of the LS174 T cells compared to HepG 2 cells. We have previously demonstrate that the 2-amino- 
1-methyl-6- phenylimidazo[4,5-b]pyridine (PhIP) heterocyclic aromatic amine, a chemical that need CYP1A2 and SULT1A1 bioactivation to form a DNA reactive metabolite, was only genotoxic in LS-174T and not in HepG2 cells (Khoury et al., 2016b). Additional experiments with specific engineered cell lines with particular bioactivation properties may allow testing this hypothesis of a possible bioactivation of AFM1 by CYP1A2 and SULT1A1 (Chevereau et al., 2017). Overall, our results suggested different independent genotoxic mechanisms of action for the aflatoxins, involving specific bioactivation pathways. The principal pathway implicated bioactivation of aflatoxins by CYP1A2 or CYP3A4 in a DNA reactive metabolite, as in HepG2 and LS-174T cells. The second pathway may implicated in specific bioactivation of aflatoxins by CYP1A2 and SULT1A1 as in the case of AFM1 in LS-174T cells. The last pathway may incriminate the bioactivation of aflatoxins by the prostaglandin $\mathrm{H}$ synthase and/or the induction of an oxidative stress like in ACHN cells. These pathways may not be exclusive from each other's and for some compounds multiple pathways may account for their genotoxic potential, depending of the bioactivation properties of the cells.

Concerning the aflatoxins precursors, we noted that OMST, NOR, AVE and CPA were devoid of genotoxic potential whatever the cell line used. These results are in agreement with some previous studies in bacteria with the Ames assay for OMST (Wehner et al., 1978), CPA (Kuilman-Wahls et al., 2002; Sabater Vilar et al., 2003; Wehner et al., 1978) and NOR (Mori et al., 1985; Wong et al., 1977). VERA demonstrated an important genotoxic potential, with the same LEC of $1 \mu \mathrm{M}$ in all cell lines and a GEF of $0.1,1$ and 10 in LS-174T, HepG2 and ACHN cells, respectively. This observation corroborated results from a mi- cronucleus study in A549 cells (Jaksic et al., 2012) and a hepatocyte/ DNA repair test (Mori et al., 1984). However, in our study VERA genotoxicity was observed whatever the cell line used, suggesting that VERA may be genotoxic independently of its bioactivation by CYPs. VERA, like AFB1, has been observed mutagenic in the Ames assay in absence of exogenous bioactivation system (Wehner et al., 1978). Inhibition of the mitochondria respiratory chain resulting in an oxidative stress had also been notice in human cells with this chemical (Kawai et al., 1983). ST demonstrated a GEF of 1 in LS174T and HepG2 cells and 10 in ACHN cells. This important genotoxic potency based on $\gamma \mathrm{H} 2 \mathrm{AX}$ assay is 10 fold higher than calculated from results with the Ames assay (McCann et al., 1975; Wong et al., 1977) but in accordance with a genotoxic study in human A549 cells (Jaksic et al., 2012). ST and VERA were the only chemicals to exhibit a GEF of 10 in ACHN cells. This feature may be linked to the sensitivity of this cell line to oxidative stress (Khoury et al., 2016b) and the possible inhibition of the mitochondria respiratory chain by VERA (Kawai et al., 1983) and ST (Kawai et al., 1986).

In conclusion, our data demonstrated the similar or greater genotoxic potential of some aflatoxin precursors compared to AFB1 in human cells and their probable carcinogenic capacity. This should be taking into account for the development of new strategies intended to reduce the aflatoxins exposure and for human risk assessment to mycotoxins.

\section{Funding}

This research was funded by the PNREST Anses, Cancer TMOI AVIESAN, 2013/1/214 and Aflafree (ANR-11- ALID-0003) grants. MG Theumer was supported by a postdoctoral fellowship from Consejo Nacional de Investigaciones Científicas y Técnicas (CONICET), Argentina. The authors also thank the French National Infrastructure of Metabolomics and Fluxomics (MetaboHUB- ANR-11-INBS-0010) for their support. 


\section{Acknowledgement}

MG Theumer is career investigator from Consejo Nacional de Investigaciones Científicas y Técnicas (CONICET), Argentina.

\section{References}

- Ando, M., Yoshikawa, K., Iwase, Y., Ishiura, S., 2014. Usefulness of monitoring gammaH2AX and cell cycle arrest in HepG2Cells for estimating genotoxicity using a highcontent analysis system. J. Biomol. Screen. 19, 1246-1254.

- Audebert, M., Zeman, F., Beaudoin, R., Pery, A., Cravedi, J.P., 2012. Comparative potency approach based on H2AX assay for estimating the genotoxicity of polycyclic aromatic hydrocarbons. Toxicol. Appl. Pharmacol. 260, 58-64.

- Battista, J.R., Marnett, L.J., 1985. Prostaglandin H synthase-dependent epoxidation of aflatoxin B1. Carcinogenesis 6, 1227-1229.

- Bryce, S.M., Bemis, J.C., Mereness, J.A., Spellman, R.A., Moss, J., Dickinson, D., Schuler, M.J., Dertinger, S.D., 2014. Interpreting in vitro micronucleus positive results: simple biomarker matrix discriminates clastogens, aneugens, and misleading positive agents. Environ. Mol. Mutagen. 55, 542-555.

- Cano, P.M., Jamin, E.L., Tadrist, S., Bourdaud'hui, P., Pean, M., Debrauwer, L., Oswald, I.P., Delaforge, M., Puel, O., 2013. New untargeted metabolic profiling combining mass spectrometry and isotopic labeling: application on Aspergillus fumigatus grown on wheat. Anal. Chem. 85, 8412-8420.

- Chevereau, M., Glatt, H., Zalko, D., Cravedi, J.P., Audebert, M., 2017. Role of human sulfotransferase $1 \mathrm{~A} 1$ and $\mathrm{N}$-acetyltransferase 2 in the metabolic activation of 16 heterocyclic amines and related heterocyclics to genotoxicants in recombinant V79 cells. Arch. Toxicol. 91, 3175-3184.

- Eaton, D.L., Gallagher, E.P., 1994. Mechanisms of aflatoxin carcinogenesis. Annu. Rev. Pharmacol. Toxicol. 34, 135-172.

- Guindon, K.A., Bedard, L.L., Massey, T.E., 2007. Elevation of 8-hydroxydeoxyguanosine in DNA from isolated mouse lung cells following in vivo treatment with aflatoxin B (1). Toxicol. Sci. 98, 57-62.

- Hamid, A.S., Tesfamariam, I.G., Zhang, Y., Zhang, Z.G., 2013. Aflatoxin B1-induced hepatocellular carcinoma in developing countries: geographical distribution, mechanism of action and prevention. Oncol Lett 5, 1087-1092.

- Holmes, R.A., Boston, R.S., Payne, G.A., 2008. Diverse inhibitors of aflatoxin biosynthesis. Appl. Microbiol. Biotechnol. 78, 559-572.

- IARC, 2012. mono100 F - 23.pdf.

- Jaksic, D., Puel, O., Canlet, C., Kopjar, N., Kosalec, I., Klaric, M.S., 2012. Cytotoxicity and genotoxicity of versicolorins and 5-methoxysterigmatocystin in A549 cells. Arch. Toxicol. 86, 1583-1591.

- Kawai, K., Nozawa, Y., Maebayashi, Y., Yamazari, M., Hamasaki, T., 1983. The inhibition of mitochondrial respiration by anthraquinone mycotoxins, averufin and versicolorins A, B. JSM Mycotoxins 18, 35-37.

- Kawai, K., Nakamaru, T., Hisada, K., Nozawa, Y., Mori, H., 1986. The effects of demethylsterigmatocystin and sterigmatin on ATP synthesis system in mitochondria: a comparison with sterigmatocystin. Mycotoxin Res. 2, 33-38.

- Kensler, T.W., Roebuck, B.D., Wogan, G.N., Groopman, J.D., 2011. Aflatoxin: a 50-year odyssey of mechanistic and translational toxicology. Toxicol. Sci. 120 (Suppl. 1), S2848. 
- Khoury, L., Zalko, D., Audebert, M., 2013. Validation of high-throughput genotoxicity assay screening using (H2AX in-cell western assay on HepG2 cells. Environ. Mol. Mutagen. 54, 737-746.

- Khoury, L., Zalko, D., Audebert, M., 2016a. Complementarity of phosphorylated histones H2AX and H3 quantification in different cell lines for genotoxicity screening. Arch. Toxicol. 90, 1983-1995.

- Khoury, L., Zalko, D., Audebert, M., 2016b. Evaluation of four human cell lines with distinct biotransformation properties for genotoxic screening. Mutagenesis 31, 83-96.

- Kuilman-Wahls, M.E., Vilar, M.S., de Nijs-Tjon, L., Maas, R.F., Fink-Gremmels, J., 2002. Cyclopiazonic acid inhibits mutagenic action of aflatoxin B(1). Environ. Toxicol. Pharmacol. 11, 207-212.

- McCann, J., Choi, E., Yamasaki, E., Ames, B.N., 1975. Detection of carcinogens as mutagens in the Salmonella/microsome test: assay of 300 chemicals. Proc. Natl. Acad. Sci. U. S. A. 72, 5135-5139.

- Meissonnier, G.M., Laffitte, J., Loiseau, N., Benoit, E., Raymond, I., Pinton, P., Cossalter, A.M., Bertin, G., Oswald, I.P., Galtier, P., 2007. Selective impairment of drug-metabolizing enzymes in pig liver during subchronic dietary exposure to aflatoxin B1. Food Chem. Toxicol. 45, 2145-2154.

- Mori, H., Kawai, K., Ohbayashi, F., Kuniyasu, T., Yamazaki, M., Hamasaki, T., Williams, G.M., 1984. Genotoxicity of a variety of mycotoxins in the hepatocyte primary culture/DNA repair test using rat and mouse hepatocytes. Cancer Res. 44, 2918-2923.

- Mori, H., Kitamura, J., Sugie, S., Kawai, K., Hamasaki, T., 1985. Genotoxicity of fungal metabolites related to aflatoxin B1 biosynthesis. Mutat. Res. 143, 121-125.

- Oda, Y., Aryal, P., Terashita, T., Gillam, E.M., Guengerich, F.P., Shimada, T., 2001. Metabolic activation of heterocyclic amines and other procarcinogens in Salmonella typhimurium umu tester strains expressing human cytochrome P4501A1, 1A2, 1B1, 2C9, 2D6, 2E1, and 3A4 and human NADPH-P450 reductase and bacterial 0acetyltransferase. Mutat. Res. 492, 81-90.

- Parveen, F., Nizamani, Z.A., Gan, F., Chen, X., Shi, X., Kumbhar, S., Zeb, A., Huang, K., 2014. Protective effect of selenomethionine on aflatoxin B1-induced oxidative stress in MDCK cells. Biol. Trace Elem. Res. 157 (3), 266-274.

- Paterson, R.R., Lima, N., 2010. Toxicology of mycotoxins. EXS 100, 31-63. Quesnot, N., Rondel, K., Audebert, M., Martinais, S., Glaise, D., Morel, F., Loyer, P.,

- Robin, M.A., 2016. Evaluation of genotoxicity using automated detection of gammaH2AX in metabolically competent HepaRG cells. Mutagenesis 31, 43-50. Sabater Vilar, M., Kuilman-Wahls, M.E., Fink-Gremmels, J., 2003. Inhibition of aflatoxin B1 mutagenicity by cyclopiazonic acid in the presence of human liver preparations. Toxicol. Lett. 143, 291-299.

- Smart, D.J., Ahmedi, K.P., Harvey, J.S., Lynch, A.M., 2011. Genotoxicity screening via the gammaH2AX by flow assay. Mutat. Res. 715, 25-31.

- Streit, E., Schwab, C., Sulyok, M., Naehrer, K., Krska, R., Schatzmayr, G., 2013. Multimycotoxin screening reveals the occurrence of 139 different secondary metabolites in feed and feed ingredients. Toxins (Basel) 5, 504-523.

- Varga, E., Glauner, T., Berthiller, F., Krska, R., Schuhmacher, R., Sulyok, M., 2013. Development and validation of a (semi-)quantitative UHPLC-MS/MS method for the determination of 191 mycotoxins and other fungal metabolites in almonds, hazelnuts, peanuts and pistachios. Anal. Bioanal. Chem. 405, 5087-5104. 
- Wehner, F.C., Thiel, P.G., van Rensburg, S.J., Demasius, I.P., 1978. Mutagenicity to Salmonella typhimurium of some Aspergillus and Penicillium mycotoxins. Mutat. Res. 58, 193-203.

- Wong, J.J., Singh, R., Hsieh, D.P., 1977. Mutagenicity of fungal metabolites related to aflatoxin biosynthesis. Mutat. Res. 44, 447-450.

- Wu, F., Khlangwiset, P., 2010. Evaluating the technical feasibility of aflatoxin risk reduction strategies in Africa. Food Addit. Contam. Part A Chem. Anal. Control Expo. Risk Assess. 27, 658-676.

- Yu, J., 2012. Current understanding on aflatoxin biosynthesis and future perspective in reducing aflatoxin contamination. Toxins (Basel) 4, 1024-1057.

\section{Table 1}

Comparison of the in vitro genotoxic potential of the aflatoxins and their precursors in the $\gamma \mathrm{H} 2 \mathrm{AX}$ In-Cell Western assay with their carcinogenic potential. Genotoxic equivalent factor (GEF) were derived from the lowest genotoxic concentration observed

\begin{tabular}{|c|c|c|c|c|}
\hline Compounds & GEF LS-174T & GEF HepG2 & GEF ACHN $^{\mathrm{a}}$ & Carcinogenesis $^{\mathrm{b}}$ \\
\hline AFB1 & 1 & 1 & 1 & + \\
\hline AFB2 & - & - & - & + \\
\hline AFG1 & 0.1 & 0.1 & 0.1 & - \\
\hline AFG2 & - & - & - & + \\
\hline AFM1 & 0.01 & - & - & + \\
\hline AFL & 1 & 1 & -10 & ND \\
\hline ST & 1 & - & 10 & + \\
\hline OMST & - & 1 & - & ND \\
\hline VERA & 0.1 & - & - & ND \\
\hline NOR & - & - & - & ND \\
\hline AVE & - & - & - & - \\
\hline CPA & - & & & - \\
\hline
\end{tabular}

${ }^{a}$ Genotoxic Equivalent Factor (GEF) derived from results observed in this study. ${ }^{b}$ Data from peer reviewed published articles and from the Carcinogenic Potency Database. Definitions: (ND) "not determined", $(+)$ tested "positive", (-) tested "negative". 


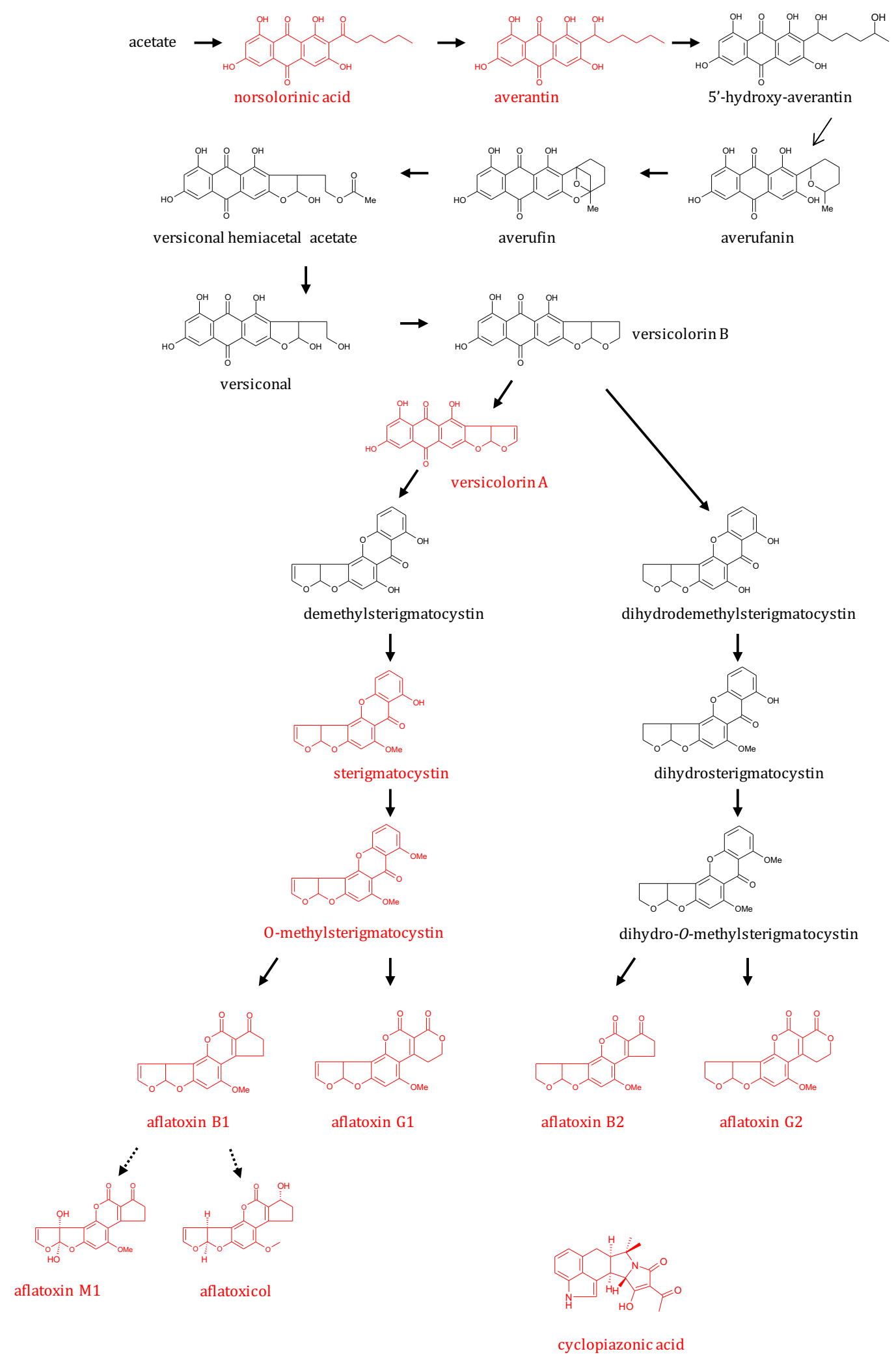

Fig. 1. Aflatoxins biosynthetic pathway. In red were presented the compounds tested in this study. 
A

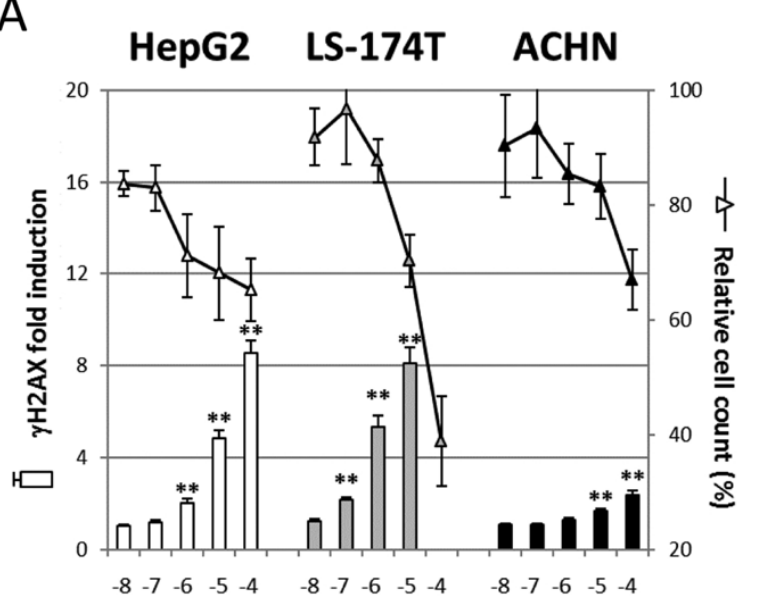

Aflatoxin B1 (M)

C

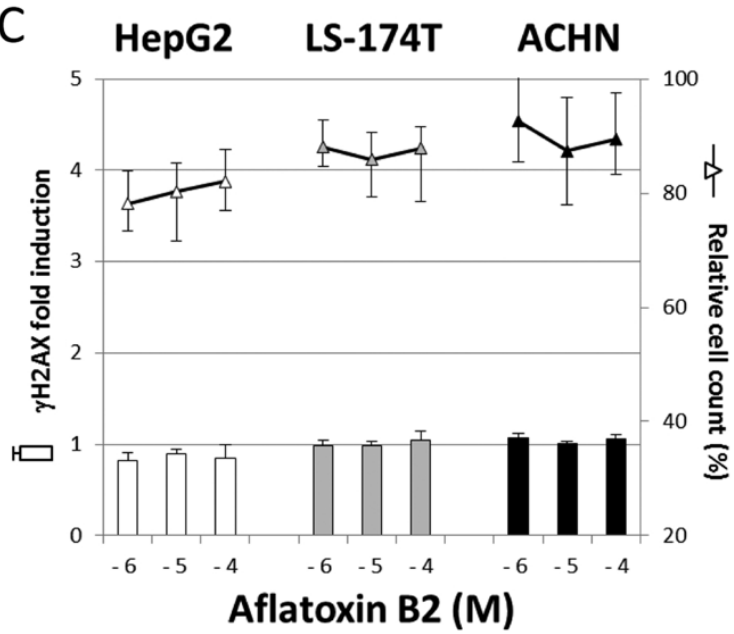

$\mathrm{E}$

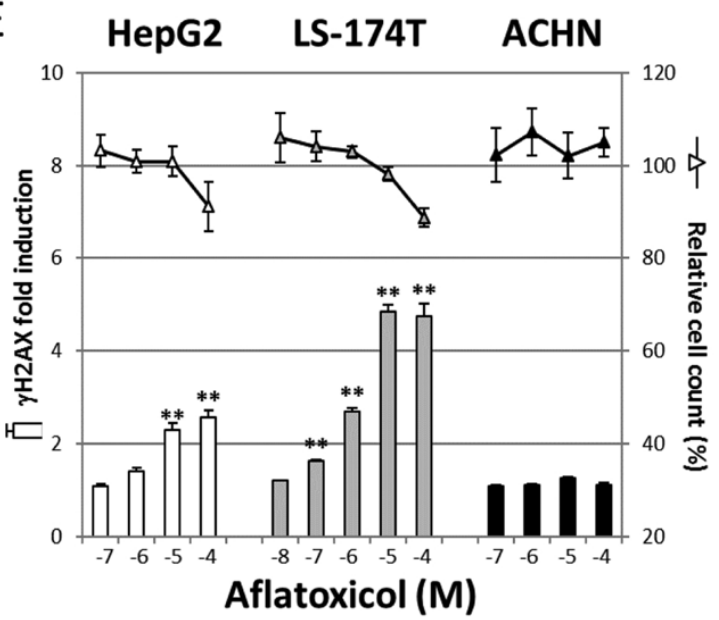

B HepG2 LS-174T ACHN

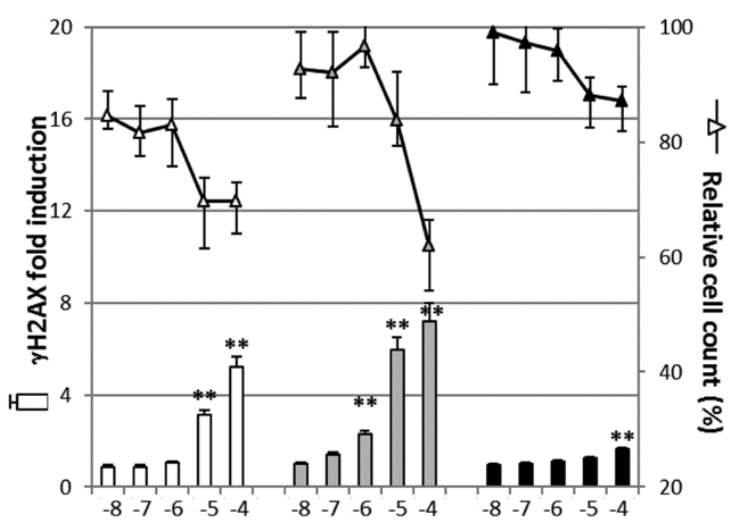

Aflatoxin G1 (M)

D HepG2 LS-174T ACHN
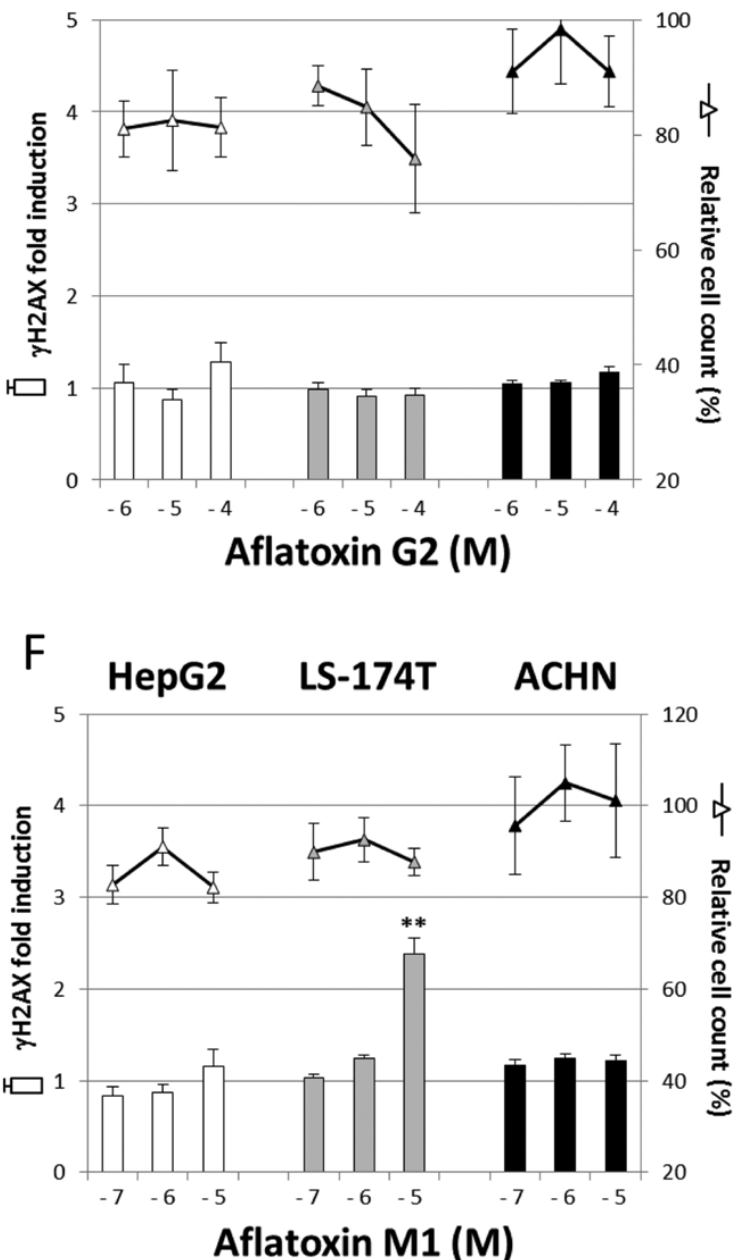

Fig. 2. In vitro cytotoxicity and genotoxicity of aflatoxins with the $\gamma \mathrm{H} 2 \mathrm{AX}$ ICW assay in HepG2, LS-174T and ACHN cell lines; aflatoxin B1 (A), aflatoxin G1 (B), aflatoxin B2 (C), aflatoxin G2 (D), aflatoxicol (E) and aflatoxin M1 (F). Each value represents the mean \pm SEM $(\mathrm{n} \geq 3$ ) after $24 \mathrm{~h}$ of treatment. Statistically significant increase in $\mathrm{H} 2 \mathrm{AX}$ phosphorylation compared with DMSO control; *, p <.05; **, p <.01. 
A

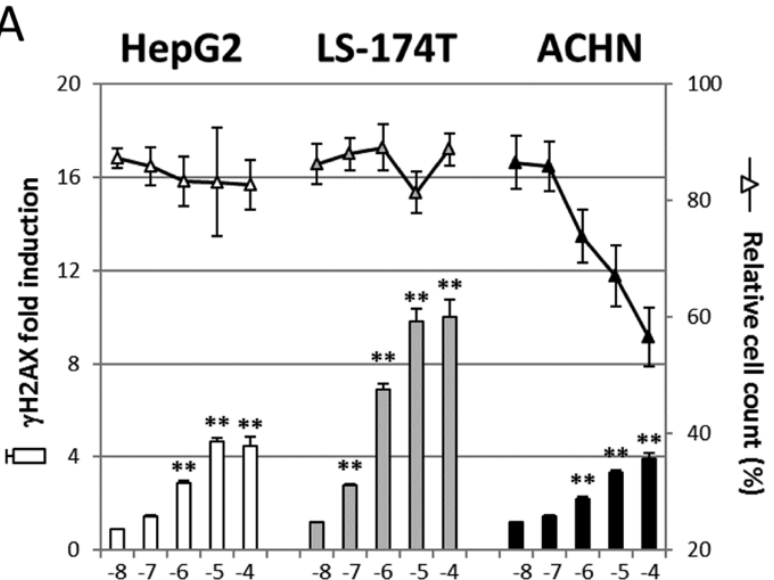

Sterigmatocystin (M)

C

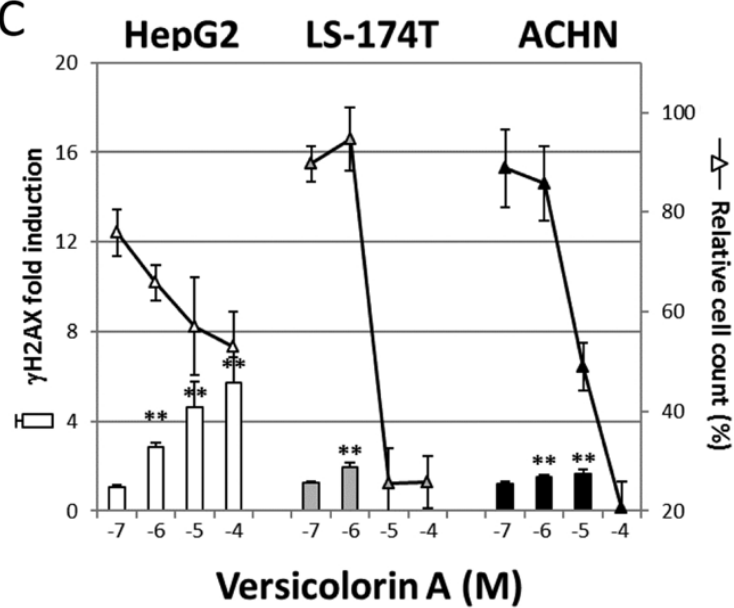

E

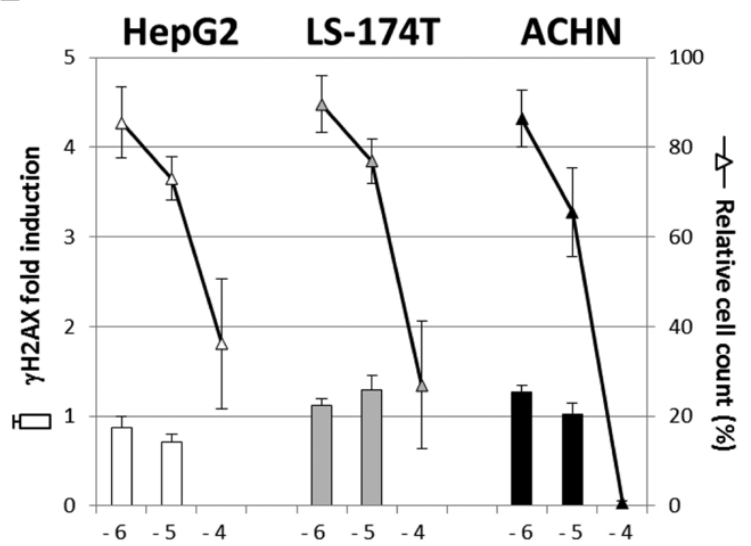

Norsolorinic acid (M)

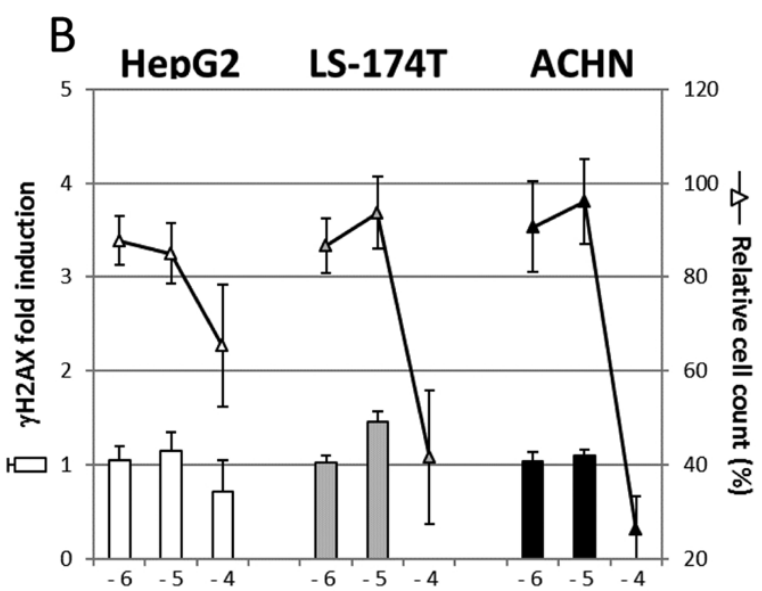

O-methyl sterigmatocystin (M)

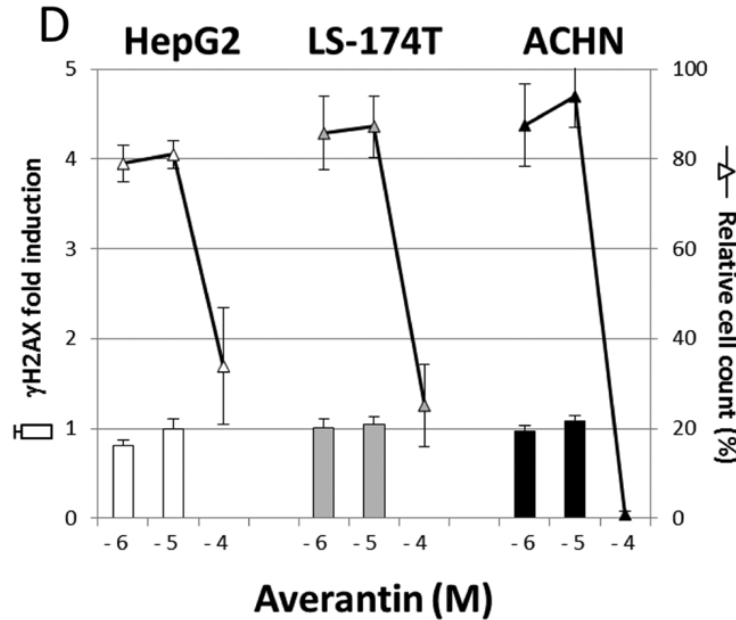

$\mathrm{F}$

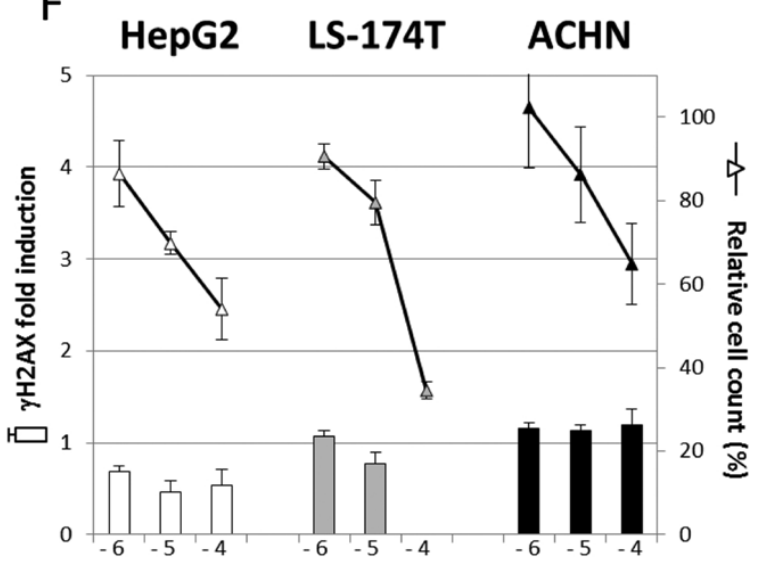

Cyclopiazonic acid (M)

Fig. 3. In vitro cytotoxicity and genotoxicity of aflatoxins precursors with the $\gamma \mathrm{H} 2 \mathrm{AX}$ ICW assay in HepG2, LS-174T and ACHN cell lines; sterigmatocystin (A), O-methyl sterigmatocystin (B), versicolorin A (C), averantin (D), norsolorinic acid (E) and cyclopiazonic acid (F). Each value represents the mean \pm SEM $(n \geq 3)$ after $24 \mathrm{~h}$ of treatment. Statistically significant increase in H2AX phosphorylation compared with DMSO control; *, $\mathrm{p}<.05 ;{ }^{* *}, \mathrm{p}<.01$. 